\title{
Anti-Cancer Effect of IN-2001 in MDA-MB-231 Human Breast Cancer
}

\author{
Kyung Nan Min, Ki Eun Joung, Dae-Kee Kim and Yhun Yhong Sheen* \\ College of Pharmacy, Ewha Womans University, Seoul 120-750, Republic of Korea
}

\begin{abstract}
In recent years, inhibition of HDACs has emerged as a potential strategy to reverse aberrant epigenetic changes associated with cancer, and several classes of HDAC inhibitors have been found to have potent and specific anticancer activities in preclinical studies. But their precise mechanism of action has not been elucidated. In this study, a novel synthetic inhibitor of HDAC, 3-(4-dimethylamino phenyl)-N-hydroxy-2-propenamide [IN-2001] was examined for its antitumor activity and the underlying molecular mechanisms of any such activity on human breast cancer cell lines. IN-2001 effectively inhibited cellular HDAC activity $\left(\right.$ IC $_{50}=$ $0.585 \mathrm{nM}$ ) inMDA-MB-231 human breast cancer cells. IN-2001 caused a significant dose-dependent inhibition of cell proliferation in estrogen receptor (ER) negative MDA-MB-231human breast cancer cells. Cell cycle analysis revealed that the growth inhibitory effects of IN-2001 might be attributed to cell cycle arrest at $G_{0} / G_{1}$ and/or $G_{2} /$ Mphase and subsequent apoptosis in human breast cancer cells. These events are accompanied by modulating several cell cycle and apoptosis regulatory genes such as CDK inhibitors $\mathrm{p} 21^{\text {WAF1 }}$ and p27 ${ }^{\mathrm{KIP} 1}$ cyclin D1, and other tumor suppressor genes such as cyclin D2. Collectively, IN-2001 inhibited cell proliferation and induced apoptosis in human breast cancer cells and these findings may provide new therapeutic approaches, combination of antiestrogen together with a HDAC inhibitor, in the hormonal therapy-resistant ER-negative breast cancers. In summary, our data suggest that this histone deacetylase inhibitor, IN-2001, is a novel promising therapeutic agent with potent antitumor effects against human breast cancers.
\end{abstract}

Key Words: IN-2001, MDA-MB-231, HDAC

\section{INTRODUCTION}

Histone acetylation is the most thoroughly studied and appreciated post-translational modification mechanism (Grunstein, 1997). Generally, transcriptionally activeeuchromatin domains tend to be relatively hyperacetylated whereas transcriptionally repressed heterochromatin domains arehypoacetylated (Göttlicher et al., 2001; Gui et al., 2004). The acetylation status of histones is regulated by the opposing action of two classes of enzymes, histone acetyl transferases (HATs) and histone deacetylases (HDACs) (Struhl, 1998; Kouzarides, 2000). Acetylation of the histone tails enhance the accessibility of transcription factors, transcriptional regulatory complexes, and RNA polymerases to promoter regions of DNA (Reynisdóttir et al., 1995; Richon et al., 2000; Roth et al., 2001; Rosato et al., 2001). This explains the role of HATs as transcriptional coactivators, and DNA binding proteins including PCAF (p300/cyclic AMP-response-element binding protein-associated factor) and members of the p300/ CBP family of transcriptional coactivators can recruit them to

\section{www.biomolther.org}

Open Access http://dx.doi.org/10.4062/biomolther.2012.20.3.313

pISSN: 1976-9148 elSSN: 2005-4483

Copyright $\odot 2012$ The Korean Society of Applied Pharmacology their site of action (Qui et al., 1999; Roth et al., 2001). However, theacetyltransferase activity of HATs extends beyonds histones; various nuclear proteins, in particular transcription factors such as p53, GATA-1, E2F, estrogen receptor, and various cellcycle regulatory proteins with variable functional consequences (Kouzarides, 2000; Roth et al., 2001; Marks et al., 2001). HDACs counteract the activity of HATs and catalyse the removal of acetyl groups from lysine residues in histone $\mathrm{N}$-terminus, leading to chromatin condensation and transcriptional repression (David et al., 1998; Davis et al., 2000; Gray and Ekström, 2001). This condensed chromatin structure inhibits transcription, presumably, because transcription factors, transcriptional regulatory complexes, and RNA polymerase do not have access to the DNA. In addition, HDACs are part of multiprotein transcriptional repressor complex or interact with DNA binding proteins. In addition to regulating the acetylation state of histones, histone deacetylase (HDAC) can bind to, deacetylate and regulate the activity of a number of other proteins, including transcription factors such as p53, E2F transcription factor 1 (E2F1), STAT1, STAT3, and nuclear factor-

Received Oct 25, 2011 Revised Nov 1, 2011 Accepted Nov 2, 2011

\section{* Corresponding Author}

E-mail: yysheen@ewha.ac.kr

Tel: +82-2-3277-3028/3025, Fax: +82-2-3277-3028 
$\kappa \mathrm{B}(\mathrm{NF}-\kappa \mathrm{B})$ and proteins with diverse biological functions such as a-tubulin, Ku70, and heat-shock protein 90 (Hsp90) (Blobel, 2000). While histones still represent primary targets for the physiological function of HDACs, the antitumor effects of HDAC inhibitors might also be attributed to transcription-independent mechanisms by modulating the acetylation status of a series of non-histone targets. HDACinhibitors can affect tumor cell growth andsurvival through multiple biological effects. HDACinhibitors induce cellcycle arrest and apoptosis, and have anti-angiogenic andimmunomodulatory effects by modulating the acetylation of a series of non-histone proteins. HDACinhibitors have been found to inducecell growth arrest, differentiation, and/orapoptosis, and exhibit potent antimetastatic, antiangiogenic, and immuno-modulatory properties in a variety of transformed cells in vitro and in vivo that cancontribute to the inhibition of tumour development andprogression (Marks et al., 2000; Johnstone, 2002; Johnstone and Licht, 2003). The treatment of normal and tumor cells with HDAC inhibitors causes a similar accumulation of acetylated histones H4, H3, H2A, H2B (Marks et al., 2001; Vigushin et al., 2001; Vigushin and Coombes, 2002). Nevertheless, tumor cells appear to be much more sensitive to growth arrest, differentiation, and apoptotic effects of these agents than normal cells (Qui et al.,1999; Butler et al., 2000a, 2000b, 2001; Krämer et al., 2001; Johnstone, 2002).

In this study, we tried to evaluate the anti-tumor effects of various HDAC inhibitors on MDA-MB-231 human breast cancer. Moreover, the underlying chemotherapeutic mechanisms of them were explored also. To examine the anti-tumor effect of HDAC inhibitors, we examined the effect of HDAC inhibitors on the cell proliferation, cell cycle distribution, and apoptosis in MDA-MB-231 human breast cancer cells. To find out the mechanism of anti-tumor activity of HDAC inhibitors, we examined the effect of IN-2001 on the expression of cell cycle regulatory protein and apoptosis-related proteins.

\section{MATERIALS AND METHODS}

\section{Chemicals}

HDAC inhibitors, such as Trichostatin A, IN2001, SAHA, and $L A Q$ were generously provided from Dr. D. K. Kim (EwhaWomansUniversity, Seoul, South Korea). HC toxin was obtained from Sigma Chemical Co. (St. Louis, MO, USA). Sodium pyrubate, penicillin-streptomycin, fetal bovine serum (FBS), trypsin-EDTA, minimum essential medium (MEM), and RPMI were acquired from GibcoBRL (Rockvulle, MD, USA). Antibodies were from Santa Crutz Biotechnology Inc. (Santa Crutz, CA, USA).

\section{Cell lines and cell culture conditions}

MDA-MB-231 cells were obtained from Korean Cell Line Bank (KCLB, Seoul, South Korea). MDA-MB-231 cells were maintained in RPMI1640 medium, supplemented with fetal bovine serum and penicillin-streptomycin. Cells were routinely maintained at $37^{\circ} \mathrm{C}$ and in $5 \% \mathrm{CO}_{2}$.

\section{Cell proliferation assay}

Cells were plated in 96 well plates and were treated with chemicals. Cells were treated with cold $10 \%$ trichloroacetic acid (TCA) and TCA-fixed cells were stained for 30 min with $0.4 \%(\mathrm{w} / \mathrm{v})$ sulforhodamineB (SRB) dissolved in $1 \%$ acetic acid. Bound dye was solubilized with $10 \mathrm{mMTris}$ base $(\mathrm{pH}$ 10.5 ) and optical dencity was read usingELISA reader (BioRad, Hercules, CA, USA) at $570 \mathrm{~nm}$.

\section{Flow Activated Cell Sorter (FACS) Analysis}

Chemicals treated cells were detached using trypsin-EDTA and fixed with $70 \%$ ethanol. After centrifugation, the cells were treated with RNase $A(10 \mu \mathrm{g} / \mathrm{ml})$ and stained with propidium iodide $(2 \mu \mathrm{g} / \mathrm{ml})$. The DNA content per cell was evaluated in a FACScalibur (Becton Dickinson,San Diego, CA, USA).

\section{RT-PCR analysis}

Total RNA was extracted using Trizol reagent (Invitrogen Co., Carlsbad, CA, USA) from cells were exposed to chemicals for $24 \mathrm{hr}$. Reverse transcription was carried out on total RNA in a mixture containing random prime, dNTPs, DTT, $\mathrm{RT}$ buffer (5X), M-MLV reverse transcriptase, RNase in at $37^{\circ} \mathrm{C}$ for $1 \mathrm{hr}$. CDNA was stored at $-20^{\circ} \mathrm{C}$ or cDNA was subjected to PCR amplification with special primer $(\mathrm{GAPDH}$; 5'ACATCgCTCAgACACCATgg3'; 5'gTAgTTgAggTCAATgAAggg3': p21; 5'gAACTTCgACTTTgTCACCgAg3'; 5'CgTTTTCgACCCTgAgAgTCTC3': Cyclin D1; 5'AgCCATggAACACCAgCTC3'; 5'gCACCTCCAgCATCCAggT3': Cyclin D2;5' TACTTCAAgTgCgTgCAgAAggAC3'; 5' TCCCACACTTCCAgTTgCgATCAT3') in reaction containing dNTP and Taqpolymerase. DNA was denatured at $95^{\circ} \mathrm{C}$ extended at $72^{\circ} \mathrm{C}$ and PCR products were analyzed on $2 \%$ agarose gels.

\section{Western blot analysis}

After the incubation with chemicals for $24 \mathrm{hr}$, cells were homogenized in a lysis buffer (Pro-prep protein extraction solution, INtRON; 20 mMTris, $160 \mathrm{mMNaCl}, 1 \mathrm{mM}$ EDTA, $1 \mathrm{mM}$ EGTA, $1 \%$ Triton $X-100,0.1 \%$ SDS, $0.25 \%$ sodium deoxycholate, $1 \mathrm{mM}$ PMSF, $1 \mathrm{mM} \mathrm{NaF}, 1 \mathrm{mM}$ dithiothreitol (DTT), $1 \mathrm{mM}$ sodium orthovanadate, pepstatin, leupeptin, and aprotinin) on ice and cell lysates were centrifuged at $14,000 \mathrm{~g}$ for $5 \mathrm{~min}$ at $4{ }^{\circ} \mathrm{C}$, divided into aliquots and stored at $-80^{\circ} \mathrm{C}$. Protein was separated by electrophoresis on $10-15 \%$ SDS-acrylamide gels and then electrophoretically transferred to polyvinylidenedifluoride (PVDF) transfer membrane (Hybond-P; Amersham). Membranes were blocked with $3 \%$ dry milk in PBST<smiles>CC(C=CC(=O)NO)C(=O)c1ccc(N(C)C)cc1</smiles>

TSA<smiles>O=C(O)C=Cc1ccc(N(CCO)CCc2cc3ccccc3[nH]2)cc1</smiles>

LAQ<smiles>NC(CCCCCC(=O)NO)c1ccccc1</smiles><smiles>CN(C)c1ccc(C(=O)NCc2ccc(C=CC(=O)C(N)O)cc2)cc1</smiles>

Fig. 1. Structures of HDAC inhibitors. 
(PBS with $0.1 \%$ Tween) over night at $4^{\circ} \mathrm{C}$ and incubated with specific first antibodies and second antibodies conjugated to horse radish peroxidase. Membranes were washed and air dried for ECL detection (ECL Plus; Amersham).

\section{RESULTS}

\section{IN-2001 causes dose-dependent growth inhibition}

In recent years, an increasing number of structurally diverse HDAC inhibitors have been identified as an exciting new class of potential anti-cancer agents. In this study, we evaluated the anti-tumor effects of various kinds of HDAC inhibitors (Fig. 1) in the human breast cancer cells in an attempt to find out better therapeutic agents for breast cancer treatment. To determine the antiproliferative effect of IN-2001 on the human breast cancer MDA-MB-231 cells were treated with vehicle (0.1\% DMSO) or various concentrations $(0.001-10 \mu \mathrm{M})$ of IN2001 for $72 \mathrm{hr}$ and then the number of cells was determined based on the SRB assay.

As shown in Fig. 2, IN-2001showed anti-proliferative effect in a dose-dependent manner. The $\mathrm{IC}_{50}$ values of HDAC inhibitors in each cell lines were shown in Table 1. These data indicated that the anti-proliferative effects of HDAC inhibitors were cell type specific and ER positive breast cancer cells seemed to be more susceptible to HDAC inhibitors than ER negative breast cancer cells.

\section{IN-2001 time-dependent growth inhibition}

In the next experiment, we carried out time-course experiment with $1 \mu \mathrm{M}$ IN-2001. As shown in Fig. 3, IN-2001 decreased the proliferation of MDA-MB-231 human breast cancer cells in a time-dependent manner. MDA-MB-231 cells

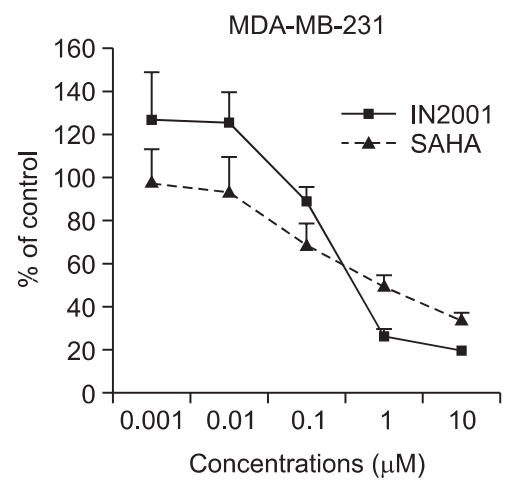

Fig. 2. Dose-dependent growth inhibition by IN-2001. MDAMB-231 human breast cancer cells were treated with vehicle $(0.1 \%$ DMSO) or indicated concentrations (0.001-10 $\mu \mathrm{M})$ of IN-2001 for $72 \mathrm{hr}$. The number of cells was determined by SRB assay andcell proliferation was expressed as percent of control. Data present mean \pm S.D. $(\mathrm{N}=4)$.

Table 1.50\% inhibitory concentration $\left(\mathrm{IC}_{50}\right)$ of HDAC inhibitor

\begin{tabular}{cc}
\hline & $\mathrm{IC}_{50}(\mu \mathrm{m})$ \\
\hline IN2001 & 0.585 \\
SAHA & 0.923 \\
\hline
\end{tabular}

showed significant growth inhibition when cells were exposed to for more than $24 \mathrm{hr}$. In MDA-MB-231 cells, cell growth was decreased by $10-15 \%$ over control with IN-2001 treatment for 24.

\section{IN-2001 induces cell cycle arrest}

To investigate whether the growth inhibitory effect of IN2001 is related to cell cycle alteration, we analyzed the cell cycle distribution of IN-2001-treated breast cancer cells. ER negative MDA-MB-231 cells were treated with vehicle $(0.1 \%$

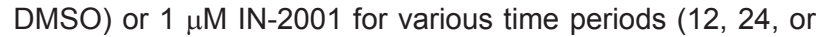
$48 \mathrm{hr}$ ) and then analyzed cell cycle distribution by flow cytometric analysis after PI staining their DNA. Representative histograms and quantitative analysis data are shown in Fig. 4 and Table 2, respectively. As shown in Fig. 4, IN-2001 showed $\mathrm{G}_{2} / \mathrm{M}$ arrest with decrease of $\mathrm{G}_{0} / \mathrm{G}_{1}$ phase or $\mathrm{S}$ phase in MDAMB-231 cells. When cells were treated with IN-2001 for 12 $\mathrm{hr}, \mathrm{MDA}-\mathrm{MB}-231$ cells yielded $42.7 \%$ of cells in $\mathrm{G}_{2} / \mathrm{M}$ phase,

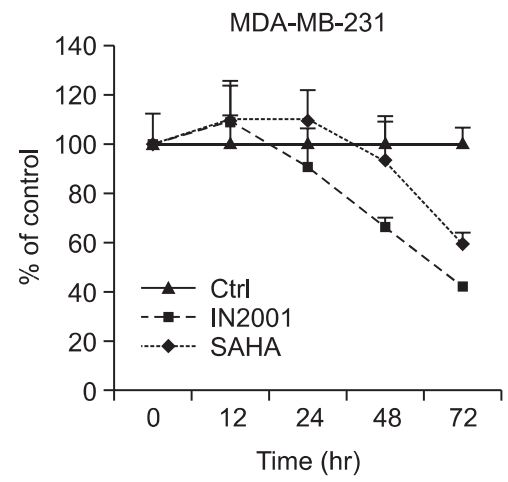

Fig. 3. Time-dependent growth inhibition by IN-2001. Human breast cancer MDA-MB-231 cells were treated with vehicle $(0.1 \%$ DMSO) or $1 \mu \mathrm{M}$ IN-2001 for various exposure time (0-72 hr). The number of cells was determined by SRB assay andcell proliferation was expressed as percent of control. Data present mean \pm S.D. $(\mathrm{N}=4)$.

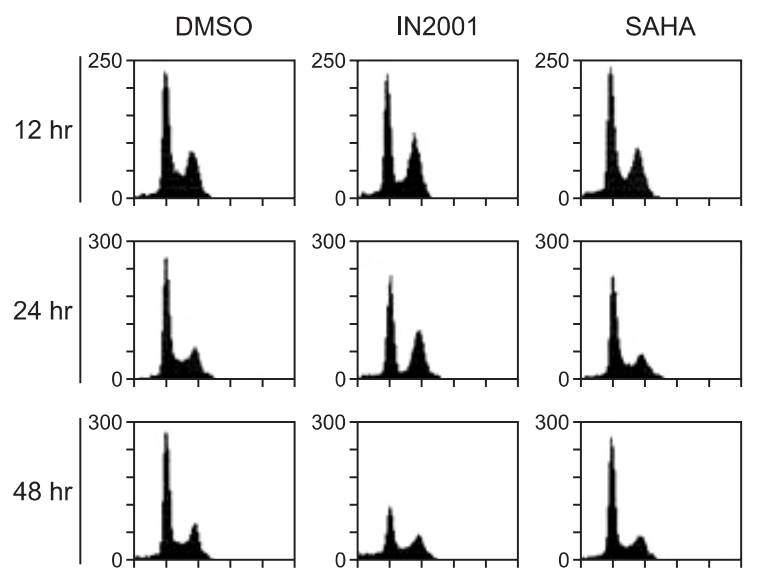

Fig. 4. Effect of IN-2001 on cell cycle distribution. MDA-MB-231. Human breast cancer cells were treated with vehicle (0.1\% DMSO) or $1 \mu \mathrm{M}$ IN-2001 for the indicated time periods. Cells were harvested, fixed, and stained with PI. Then 20,000 stained cells were subjected to flow cytometry analysis to determine the distribution of cells. 
Table 2. Cell cycle distriburtion by IN-2001

\begin{tabular}{|c|c|c|c|c|c|}
\hline \multirow{2}{*}{ Times (hr) } & \multirow{2}{*}{$\begin{array}{c}\text { HDAC } \\
\text { inhibitors }\end{array}$} & \multicolumn{4}{|c|}{ Distributions of cells (\%) } \\
\hline & & Sub-G 1 & $\mathrm{G}_{0} / \mathrm{G}_{1}$ & S & $\mathrm{G}_{2} / \mathrm{M}$ \\
\hline \multirow[t]{3}{*}{12} & Ctrl & $1.706 \pm 0.212$ & $53.832 \pm 0.655$ & $11.487 \pm 0.291$ & $34.314 \pm 0.731$ \\
\hline & IN2001 & $2.376 \pm 0.281$ & $49.477 \pm 0.883$ & $7.878 \pm 0.267$ & $42.667 \pm 1.089^{*}$ \\
\hline & SAHA & $2.678 \pm 0.352$ & $54.997 \pm 1.681$ & $10.299 \pm 0.436$ & $33.762 \pm 1.369$ \\
\hline \multirow[t]{3}{*}{24} & Ctrl & $2.067 \pm 0.151$ & $59.915 \pm 0.916$ & $12.870 \pm 0.211$ & $26.936 \pm 0.714$ \\
\hline & IN2001 & $2.845 \pm 0.237$ & $52.017 \pm 1.137$ & $5.565 \pm 0.284$ & $42.418 \pm 0.906^{*}$ \\
\hline & SAHA & $3.078 \pm 0.027$ & $60.993 \pm 0.481$ & $12.502 \pm 0.702$ & $26.497 \pm 0.555$ \\
\hline \multirow[t]{3}{*}{48} & Ctrl & $2.583 \pm 0.155$ & $61.213 \pm 1.107$ & $10.910 \pm 0.112$ & $27.275 \pm 1.182$ \\
\hline & IN2001 & $7.595 \pm 0.802$ & $49.338 \pm 0.645$ & $11.542 \pm 0.480$ & $39.458 \pm 0.796^{*}$ \\
\hline & SAHA & $3.474 \pm 0.712$ & $62.667 \pm 1.675$ & $10.879 \pm 0.590$ & $26.103 \pm 1.341$ \\
\hline
\end{tabular}

*Bold lettering indicates significant difference from control group $(p<0.05)$.

$$
\text { p21 }{ }^{\text {WAF1 }} \text { mRNA level }
$$
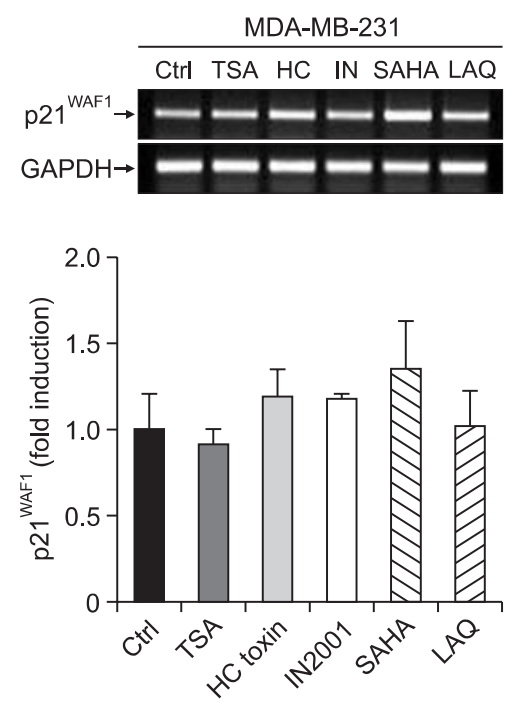

Fig. 5. Effect of HDAC inhibitor on the expression of cdk inhibitor. MDA-MB-231 cells were treated with vehicle $(0.1 \%$ DMSO) or $1 \mu \mathrm{M}$ HDAC inhibitors for $24 \mathrm{hr}$. Total RNA was isolated and then subjected to RT-PCR using specific primers. GAPDH served as loading control. For quantification, the band intensity of p21WAF1 was normalized to that of GAPDH and data was expressed as fold induction compared to control group.

whereas untreated control cells showed $34.3 \%$ of cells in $\mathrm{G}_{2} / \mathrm{M}$ phase. With $24 \mathrm{hr}$ treatment IN-2001 accumulated $42.4 \%$ of cells in $G_{2} / M$ phase, whereas untreated control cells showed $26.9 \%$ of cells in $\mathrm{G}_{2} / \mathrm{M}$ phase. When cells were treated with IN2001 for $48 \mathrm{hr}$ showed $39.5 \%$ of cells in $\mathrm{G}_{2} / \mathrm{M}$ phase, whereas untreated control cells showed $27.3 \%$ of cells in $\mathrm{G}_{2} / \mathrm{M}$ phase. SAHA did not affect cell cycle distribution of MDA-MB-231 cells.

\section{IN-2001 increases p21 ${ }^{\text {WAF1 } 1}$ and p2 $7^{\mathrm{KIP} 1}$ expression}

In the previous study, we found that HDAC inhibitors induced cell cycle arrest. In relation to cell cycle arrest, we examined the effects of HDAC inhibitorson the cell cycle regulatory proteins, such as cyclins and cyclin dependent kinase (cdk) inhibitors.MDA-MB-231 cells were treated with vehicle ( $0.1 \%$ DMSO) or $1 \mu \mathrm{M}$ IN-2001 for $24 \mathrm{hr}$. And then the expression of cdk inhibitors, such as p2 $1^{\text {WAF1 }}$ and $\mathrm{p} 27^{\mathrm{KIP} 1}$ was examined by RT-PCR and western blot analysis. As shown in Fig. 5 in MDA-MB-231 cells, IN2001, and SAHA slightly increased p21 $1^{\text {WAF1 }}$ mRNA level. In contrast, p21 ${ }^{\text {WAF1 }}$ protein level was significantly up-regulated by all kinds of IN-2001 (Fig. 6). IN2001, and SAHA treatment showed 1.9-fold, and 1.4-fold increase in $221^{\text {WAF } 1}$ protein level, respectively. In addition, p27 KIP1 protein level was also increased to 2.6 -fold, and 1.5 -fold with IN2001, and SAHA, respectively.

These results suggested that the HDAC inhibitor-induced up-regulation of cdk inhibitor may lead to cell cycle arrest, ultimately resulting in growth inhibition.

\section{IN-2001 decreases cyclin D1 expression and increases cyclin D2 expression}

As well as cdk inhibitors, one of the important cell cycle regulatoryproteins is cyclin. In this study, we examined the effect of IN-2001 on the expressions of D-type cyclin (cyclin D1 and cyclin D2). MDA-MB-231 cells were treated with vehicle $(0.1 \%$

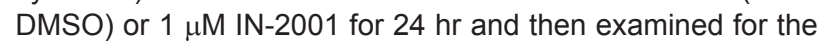
expression of cyclin D1 and cyclin D2 by RT-PCR analysis. In MDA-MB-231 cells, TSA, HC toxin, and LAQ significantly down-regulated cyclin D1 mRNA level but did not change cyclin D2 mRNA level. Cyclin D2 mRNA level was up-regulated by IN2001 and SAHA to 1.6-fold and 1.8-fold, respectively (Fig. 7).

\section{HDAC inhibitor decreases thymidylate synthase expres- sion}

Thymidylate synthase (TS) is an essential enzyme for DNA replication and repair because it provides the sole intracellular source of dTMP. Thus, it has been a major target of chemotherapeutic agents, such as fluoropyrimidines (i.e. 5-FU) and antifolates (i.e. TDX, ZD931, and MTA). Therefore, we examined the effect of HDAC inhibitor on the TS gene expression. MDA-MB-231 cells were treated with vehicle (0.1\% DMSO) or $1 \mu \mathrm{M}$ HDAC inhibitors for $24 \mathrm{hr}$ and then TS mRNA level was determined using RT-PCR technique. As shown in Fig. 8, TSA, HC toxin, IN2001, and LAQ treatment decreased TS mRNA level to $24 \%, 22 \%, 80 \%$, and $33 \%$ of control level, respectively in MDA-MB-231 cells. But SAHA did not show sig- 

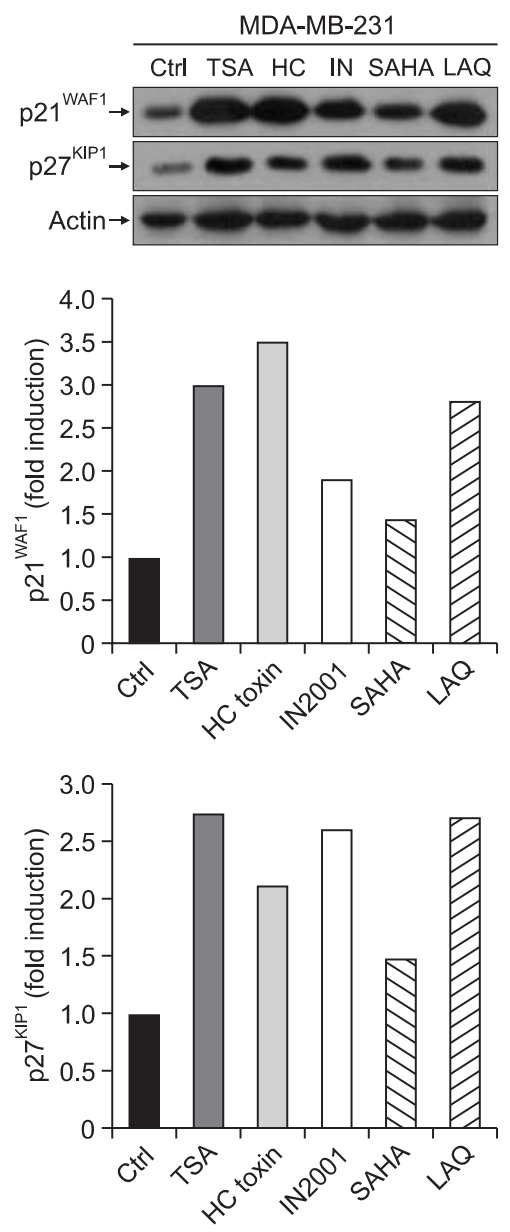

Fig. 6. Effect of IN-2001 on the expression of cdk inhibitor. MDAMB-231 cells were treated with vehicle $(0.1 \% \mathrm{DMSO})$ or $1 \mu \mathrm{M} \mathrm{IN}$ 2001 for24 hr.Protein extracts were prepared and $50 \mu \mathrm{g}$ of protein extracts were separated by $12 \%$ SDS-PAGE. Blots were probed with the corresponding antibodies. Actin served as the loading control. For quantification, the band intensity of $\mathrm{p} 21^{\mathrm{WAF} 1}$ and $\mathrm{p} 27^{\mathrm{KIP} 1}$ was normalized to that of Actin and data was expressed as fold induction compared to control group.

nificant changes in TS expression, instead slightly increased TS expression.

\section{HDAC inhibitor induces dose-dependent apoptosis}

To determine whether anti-proliferative effect of HDAC inhibitor is related with induction of apoptosis, we examined the effect of HDAC inhibitor on the apoptosis. Moreover, we tried to elucidate the underlying mechanism of apoptosis induced by HDAC inhibitors. MDA-MB-231 cells treated with vehicle (0.1\% DMSO) or $1 \mu \mathrm{M}$ HDAC inhibitors for various time period $(12 \mathrm{hr}, 24 \mathrm{hr}$, or $48 \mathrm{hr}$ ). And then cell were stained with fluorescent $\mathrm{PI}$ dye and then subjected to FACS analysis to measure the sub-G $G_{1}$ populations, which represent apoptotic cells with less than 2N DNA content. In MDA-MB-231 cells, 1 $\mu$ MHDAC inhibitors did not show significant sub-G peak when cells were exposed for $12 \mathrm{hr}$. As the exposure time increased, apoptotic cells were detected. TSA, HC toxin, and LAQ treatement for $24 \mathrm{hr}$ showed $7 \%, 7.6 \%$, and $8 \%$ of sub-G peak, respectively, whereas untreated control cells showed $2.1 \%$ of
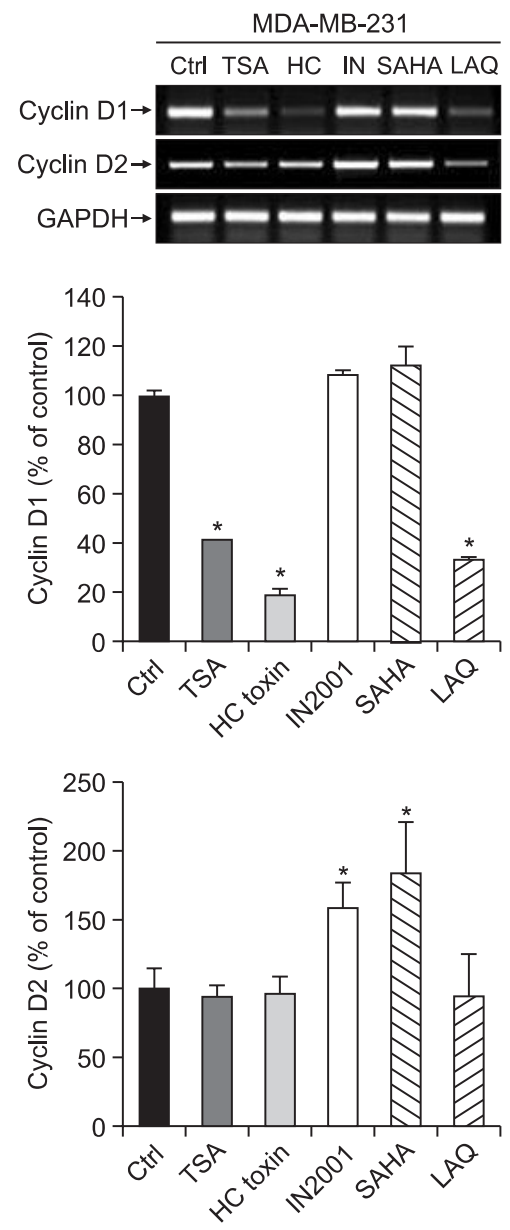

Fig. 7. Effect of IN-2001 on the cyclin D expression. MDA-MB-231 cells were treated with vehicle $(0.1 \%$ DMSO) or $1 \mu \mathrm{M} I N-2001$ for $24 \mathrm{hr}$. Total RNA was isolated and then subjected to RT-PCR using specific primers. GAPDH served as the loading control. For quantification, the band intensity of cyclin $D$ was normalized to that of GAPDH and data was expressed as fold induction compared to control group $(p<0.05)$. *Significantly different from control.

sub-G, peak. When cells were exposed to HDAC inhibitors for $48 \mathrm{hr}, \mathrm{HDAC}$ inhibitors except SAHA increased apoptotic peak ranging from $7.6 \%$ to $12.9 \%$ compared to the control value of $2.6 \%$. However, $1 \mu \mathrm{M}$ SAHA did not show apparent apoptotic sub-G ${ }_{1}$ peak (Fig. 9).

\section{DISCUSSION}

In cancer, some genes are transcriptionally silenced by the inappropriated recruitment of HDACs, e.g., tumor suppressor genes (Glaser et al., 2003). Known repressors are multiproteins that contain DNA binding proteins (e.g., NcoR, SMRT, MEF, MeCP2, and sin3A) that commonly use HDACs to repress transcription and block the function of the tumor suppressor gene. The arche-typical gene silenced in this manner in human cancer is the cyclin-dependent kinase inhibitor p21 WAF1. Epigenetic reactivation of p21 WAF1 by HDAC inhibitors has been reported in cancer cell lines (Archer et al., 1998), and the restoration of $\mathrm{p} 21^{\text {WAF1 }}$ gene expression by HDAC inhibitors 

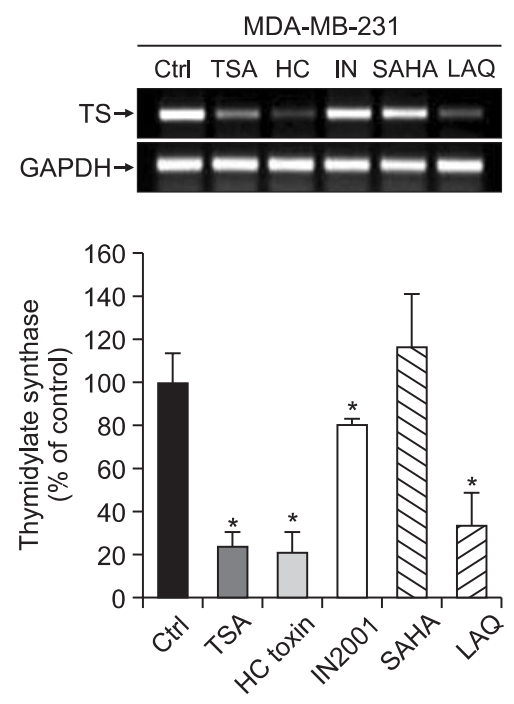

Fig. 8. Effect of HDAC inhibitor on the thymidylate synthase expression. MDA-MB-231cells were treated with vehicle $(0.1 \%$ DMSO) or $1 \mu \mathrm{M}$ HDAC inhibitors for $24 \mathrm{hr}$. Total RNA was isolated and then subjected to RT-PCR using specific primers for thymidylate synthase. GAPDH served as the loading control. For quantification, the band intensity of TS was normalized to that of GAPDH and data was expressed as fold induction compared to control group. ${ }^{*}$ Significantly different from control $(p<0.05)$.

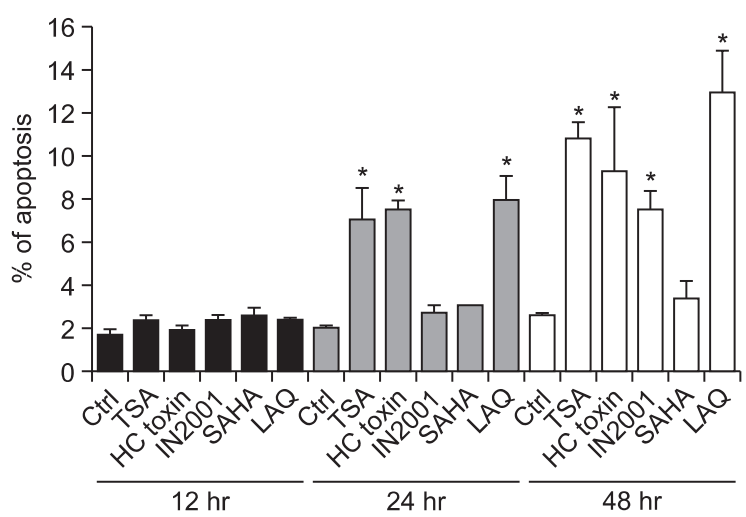

Fig. 9. Quantitative analysis of HDAC inhibitor-induced apoptosis. MDA-MB-231 cells were treated with vehicle $(0.1 \%$ DMSO) or $1 \mu \mathrm{M}$ HDAC inhibitors for 12,24 or 48 hr. Cells were harvested, fixed, and stained with PI. Then 20,000 stained cells were subjected to flow cytometry analysis. Quantitative analysis of apoptosis was done using ModiFit program. Data present mean \pm S.D. $(N=4)$. *Significantly different from control at each time point $(p<0.05)$.

is associated with enrichment of hyperacetylated histones at the p21 ${ }^{\text {WAF1 }}$ promoter (Gui et al., 2004). Demethylatingagents such as 5-aza-2'-deoxycytidine are particularly interesting owing to the interaction of DNA methylation with histone deacetylation in gene silencing of tumor suppressor genes. Combinations of 5-aza-2'-deoxycytidine with HDAC inhibitors, TSA or depsipeptide, were shown to reactivate silenced tumor suppressor genes including MLH1, TIMP3, CDKN2B, CDKN2A, $\mathrm{ARHI}$, gelsolin, and maspin, synergistically increasing the level of tumor cell apoptosis (Drummond et al., 2005). Marks et al. (2001) have proposed a mechanism of action of HDAC inhibitors that induce tumor growth arrest, differentiation, and/ or apoptosis. With inhibition of HDAC, histones are acetylated, and the DNA that is tightly wrapped around a highly charged deacetylated histone core relaxes. Inhibition of HDAC activity generates acetylation of histones in nucleosomes, resulting in a more open chromatin structure. The relaxed chromatin structure allows expression of specific set of programmed genes, which, in turn, leads to cell growth arrest, differentiation, and/or apoptotic cell death and, as a consequence, inhibition of tumor growth. HDAC inhibitors may achieve their antitumor effects through reactivation of dormant tumor suppressor genes (Finnin et al., 2001; Finzer et al., 2001; Furumai et al., 2001; Fournel et al., 2002; Villar-Garea et al., 2004). In addition to stand alone-therapeutics for chemotherapy, HDAC inhibitors seem to be suitable for combination therapy as "sensitizer drugs", enhancing the antitumor effects of specific chemotherapeutics. In fact, a proportion of the clinical trials using HDAC inhibitors involve a combination of an established antitumor compound together with a HDAC inhibitor (Cress and Seto, 2000; Chan et al., 2001; de Ruijter et al., 2003; Villar-Garea et al.,2004). The drug combinations may have 2 advantages: first, the dose of each substance necessary for cell growth inhibition or apoptosis is usually much lower than if used separately, reducing side effects and toxicity, and second, resistance to certain chemicals can be overcome in some cases by combining drugs. For instance, cell death after treatment with etoposide, comptothecin, and other substances that cross-link DNA and Topo II enzymes increases if the cell lines are pretreated with either TSA and SAHA, probably because the chromatin changes caused by the hydroxamic acids facilitate cross-linker access to the target. Combinations of nuclear receptor ligands, such as all trans retinoic acid (ATRA), or vitamin $D$ analaogs, such as 1,25-dihydroxyvitamin $D$, with HDAC inhibitors have been shown to increase differentiation and apoptosis in cancer cells and also inhibit tumor growth in vivo (Banwell et al., 2003; Bulavin et al., 2004; Drummond et al., 2005).

\section{ACKNOWLEDGMENTS}

This work was supported by grant 2006-KRF-531-E00112 from KOSEF.

\section{REFERENCES}

Archer. S. Y., Meng. S., Shei. A. and Hodin. R. A. (1998) p21(WAF1) is required for butyrate-mediated growth inhibition of human colon cancer cells. Proc. Natl. Acad. Sci. USA 95, 6791-6796.

Banwell, C. M., Singh, R., Stewart, P. M., Uskokovic, M. R. and Campbell, M. J. (2003) Antiproliferative signalling by $1,25(\mathrm{OH}) 2 \mathrm{D} 3$ in prostate and breast cancer is suppressed by a mechanism involving histone deacetylation. Recent Results Cancer Res. 164, 83-98.

Blobel, G. A. (2000) CREB-binding protein and p300: molecular integrators of hematopoietic transcription. Blood 95, 745-755.

Bulavin, D. V., Phillips, C., Nannenga, B., Timofeev, O., Donehower, L. A., Anderson, C. W., Appella, E. and Fornace, A, J. Jr. (2004) Inactivation of the Wip1 phosphatase inhibits mammary tumorigenesis through p38 MAPK-mediated activation of the p16(Ink4a)-p19(Arf) pathway. Nat. Genet. 36, 343-350.

Butler, L. M., Agus, D. B., Scher, H. I., Higgins, B., Rose, A., CordonCardo, C., Thaler, H. T., Rifkind, R. A., Marks, P. A. and Richon, V. M. (2000a) Suberoylanilide hydroxamic acid, an inhibitor of histone 
deacetylase, suppresses the growth of prostate cancer cells in vitro and in vivo. Cancer Res. 60, 5165-5170.

Butler, L. M., Higgins, B., Fox, W. D., Agus, D. B., Cordon-Cardo, C. and Scher, H. J. (2000b) Hybrid polar inhibitors of histone deacetylase suppress the growth of the CWR22 human prostate cancer xenograft. Proc. Am. Assoc. Cancer Res. 41, 289

Butler, L. M., Webb, Y., Agus, D. B., Higgins, B., Tolentino, T. R., Kutko, M. C., LaQuaglia, M. P., Drobnjak, M., Cordon-Cardo, C., Scher, H. I., Breslow, R., Richon, V. M., Rifkind, R. A. and Marks, P. A. (2001) Inhibition of transformed cell growth and induction of cellular differentiation by pyroxamide, an inhibitor of histone deacetylase. Clin. Cancer Res. 7, 962-970.

Chan, H. M., Krstic-Demonacos, M., Smith, L., Demonacos, C and La Thangue, N. B. (2001) Acetylation control of the retinoblastoma tumour-suppressor protein. Nat. Cell Biol. 3, 667-674.

Cress, W. D. and Seto, E. (2000) Histone deacetylases, transcriptional control, and cancer. J. Cell Physiol. 184, 1-16.

David, G., Alland, L., Hong, S. H., Wong, C. W., DePinho, R. A. and Dejean, A. (1998) Histone deacetylase associated with mSin3A mediates repression by the acute promyelocytic leukemia-associated PLZF protein. Oncogene 16, 2549-2556.

Davis, T., Kennedy, C., Chiew, Y. E., Clarke, C. L. and deFazio, A. (2000) Histone deacetylase inhibitors decrease proliferation and modulate cell cycle gene expression in normal mammary epithelial cells. Clin. Cancer Res. 6, 4334-4342.

de Ruijter, A. J., van Gennip, A. H., Caron, H. N., Kemp, S. and van Kuilenburg, A. B. (2003) Histone deacetylases (HDACs): characterization of the classical HDAC family. Biochem. J. 370, 737-749.

Drummond, D. C., Noble, C. O., Kirpotin, D. B., Guo, Z., Scott, G. K. and Benz, C. C. (2005) Clinical development of histone deacetylase inhibitors as anticancer agents. Annu. Rev. Pharmacol. Toxicol. 45, 495-528.

Finnin, M. S., Donigian, J. R. and Pavletich, N. P. (2001) Structure of the histone deacetylase SIRT2. Nat. Struct. Biol. 8, 621-625.

Finzer, P., Kuntzen, C., Soto, U., zur Hausen, H. and Rösl, F. (2001) Inhibitors of histone deacetylasearrest cell cycle and induce apoptosis in cervical carcinoma cells circumventing human papillomavirus oncogene expression. Oncogene 20, 4768-4776.

Fournel, M., Trachy-Bourget, M. C., Yan, P. T., Kalita, A., Bonfils, C., Beaulieu, C., Frechette, S., Leit, S., Abou-Khalil, E., Woo, S. H., Delorme, D., MacLeod, A. R., Besterman, J. M. and Li, Z. (2002) Sulfonamide anilides, a novel class of histone deacetylase inhibitors, are antiproliferative against human tumors. Cancer Res. 62 , 4325-4330

Furumai, R., Komatsu, Y., Nishino, N., Khochbin, S., Yoshida, M. and Horinouchi, S. (2001) Potent histone deacetylase inhibitors built from trichostatin $A$ and cyclic tetrapeptide antibiotics including trapoxin. Proc. Natl. Acad. Sci. USA 98, 87-92.

Glaser, K. B., Staver, M. J., Waring, J. F., Stender, J., Ulrich, R. G. and Davidsen,S. K. (2003) Gene expression profiling of multiple histone deacetylase (HDAC) inhibitors: defining a common gene set produced by HDAC inhibition in T24 and MDA carcinoma cell lines. Mol. Cancer Ther. 2, 151-163.

Göttlicher, M., Minucci, S., Zhu, P., Krämer, O. H., Schimpf, A., Giavara, S., Sleeman, J. P., Lo Coco, F., Nervi, C., Pelicci, P. G. and
Heinzel, T. (2001) Valproicacid defines a novel class of HDAC inhibitors inducing differentiation of transformed cells. EMBO J. 20 , 6969-6978.

Gray, S. G. and Ekström, T. J. (2001) The human histone deacetylase family. Exp. Cell Res. 262, 75-83.

Grunstein, M. (1997) Histone acetylation in chromatin structure and transcription. Nature 389, 349-352.

Gui, C. Y., Ngo, L., Xu, W. S., Richon, V. M. and Marks, P. A. (2004) Histone deacetylase (HDAC) inhibitor activation of p21WAF1 involves changes in promoter-associated proteins, including HDAC1. Proc. Natl. Acad. Sci. USA 101, 1241-1246.

Johnstone, R. W. (2002) Histone-deacetylase inhibitors: novel drugs for the treatment of cancer. Nat. Rev. Drug. Discov. 1, 287-299.

Johnstone, R. W. and Licht, J.D. (2003) Histone deacetylase inhibitors in cancer therapy: is transcription the primary target? Cancer Cell 4, 13-18.

Kouzarides, T. (2000) Acetylation: a regulatory modification to rival phosphorylation? EMBO J. 19, 1176-1179.

Krämer, O. H., Göttlicher, M. and Heinzel, T. (2001) Histone deacetylase as a therapeutic target. Trends Endocrinol. Metab. 12, 294300.

Marks, P.A., Rifkind, R.A., Richon, V.M., Breslow, R., Miller, T. and Kelly, W.K. (2001) Histone deacetylases and cancer: causes and therapies. Nat. Rev. Cancer 1, 194-202.

Qui, L., Kelso, M. J., Hansen, C., West, M. L., Fairlie, D. P. and Parson, P. G. (1999) Anti-tumouractivity in vitro and in vivo of selective differentiating agents containing hydroxamate. Br. J. Cancer $\mathbf{8 0}$ 1252-1258.

Reynisdóttir, I., Polyak, K., lavarone, A. and Massagué, J. (1995) Kip/ Cip and Ink4 Cdk inhibitors cooperate to induce cell cycle arrest in response to TGF-beta. Genes Dev. 9, 1831-1845.

Richon, V. M., Sandhoff, T. W., Rifkind, R. A. and Marks, P. A. (2000) Histone deacetylase inhibitor selectively induces p21WAF1 expression and gene-associated histone acetylation. Proc. Natl. Acad. Sci. USA 97, 10014-10019.

Rosato, R. R., Wang, Z., Gopalkrishnan, R. V., Fisher, P. B. and Grant, S. (2001) Evidence of a functional role forthe cyclin-dependent kinase-inhibitor p21WAF1/CIP1/MDA6 in promoting differentiation and preventing mitochondrial dysfunction and apoptosis induced by sodium butyrate in human myelomonocytic leukemia cells (U937). Int. J. Oncol. 19, 181-191.

Roth, S. Y., Denu, J. M. and Allis, C. D. (2001) Histone acetyltransferases. Annu. Rev. Biochem. 70, 81-120.

Struhl, K. (1998) Histone acetylation and transcriptional regulatory mechanisms. Genes Dev. 12, 599-606.

Vigushin, D. M., Ali, S., Pace, P. E., Mirsaidi, N., Ito, K., Adcock, I. and Coombes, R. C. (2001) Trichostatin A is a histone deacetylase inhibitor with potent antitumor activity against breast cancer in vivo. Clin. Cancer Res. 7, 971-976.

Vigushin, D. M. and Coombes, R. C. (2002) Histone deacetylase inhibitors in cancer treatment. Anticancer Drugs 13, 1-13.

Villar-Garea, A. and Esteller, M. (2004) Histone deacetylase inhibitors: understanding a new wave of anticancer agents. Int. J. Cancer 112, 171-178. 